\title{
Redes discursivas: animais, campo, Matemática escolar e contribuições metodológicas da análise de redes
}

\author{
Discursive networks: animals, countryside, scholar Mathematics and \\ methodological contributions to network analysis
}

\author{
Vanessa Franco Neto \\ Angela Maria Guida
}

\begin{abstract}
Resumo: O presente artigo investiga dez livros didáticos de Matemática distribuídos entre os anos de 2013 a 2018 em escolas do campo no Brasil no âmbito do Programa Nacional do Livro Didático em sua versão para o Campo, o PNLD Campo. As análises tomam os Estudos Animais como mote para discutir as subjetividades produzidas neste contexto. As teorizações foucaultianas são adotadas para examinar as redes discursivas descritas e inquiridas a partir do uso de dois softwares de análise qualitativa e quantitativa, o Atlas TI e o Gephi. A articulação da teorização empregada com os softwares se ampara na análise do conceito conectado. Os resultados mostram que os animais são posicionados nesses materiais ora como dispositivo pedagógico, a fim de captar a atenção e engajamento dos estudantes em seus processos de ensino e de aprendizagem da Matemática escolar, ora os engajam em um processo de exploração de suas vidas para sustentar uma racionalidade que distribui, organiza e mantém políticas da vida e da morte.
\end{abstract}

Palavras-chave: Animais. Campo. Matemática Escolar. Análise de Redes.

Abstract: This paper investigates ten mathematics textbooks distributed between the years of 2013 to 2018 in countryside schools in Brazil within the scope of the Textbook National Program in its version for the Countryside, the PNLD Campo. The analyzes take the Animal Studies as a motto to discuss the subjectivities produced in this context. The Foucaultian theorizations are adopted to examine the discursive networks described and inquired from the use of two qualitative and quantitative analysis software, Atlas $\mathrm{TI}$ and Gephi. The articulation of the theorization employed with the software is supported by the analysis of the Connected Concept Analysis. The results show that the animals are positioned in these materials sometimes take them as a pedagogical device, in order to capture students' attention and engagement in their teaching and learning processes in school Mathematics, while at other times they are engaged in a process of exploration of their lives to sustain a rationality that distributes, organizes, and maintains policies of life and death.

Vanessa Franco Neto Doutora em Educação Matemática (UFMS). Professora da Universidade Federal de Mato Grosso do Sul (UFMS), campus Campo Grande. Mato Grosso do Sul, Brasil. $\$ vanfneto@gmail.com

Angela Maria Guida Doutora em Letras (UFRJ) Professora do Programa de PósGraduação em Educação Matemática da Universidade Federal de Mato Grosso do Sul (UFMS). Mato Grosso do Sul, Brasil. angelaguida.ufms@gmail.com

Recebido em 05/03/2019 Aceito em 30/03/2019 Publicado em 01/05/2019

Keywords: Animals. Countryside. Scholar Mathematics. Network Analysis.

\section{Introdução}

O objetivo deste artigo é mapear e problematizar as discursividades que percorrem livros didáticos de Matemática dos anos iniciais de escolas do campo no Brasil produzidos no contexto do Programa Nacional do Livro Didático em sua versão para o Campo (o PNLD Campo) que 
acabam por constituir uma rede discursiva que mobiliza noções robustas acerca do sujeito desejável no contexto do campo.

Nesse sentido, são propostos dois questionamentos que balizam os processos analíticos. Primeiramente, indaga-se de que maneiras os livros de Matemática contribuem para a constituição do sujeito desejável no contexto do campo e, simultaneamente, quais seriam os conhecimentos de Matemática necessários para o exercício desse modo de vida.

Esse perscrutar tem sido feito por meio de uma investigação sobre os materiais mencionados que resultou na catalogação de um total de 160 códigos, elaborados por nós, destacando discursividades que orbitavam as práticas do campo, em atividades relacionadas ao currículo de Matemática escolar, a fim de descrever e analisar a constituição desse sujeito com 0 tratamento a luz de teorizações contemporâneas. Todo esse procedimento tem sido elaborado em uma investigação que procura descrever o sujeito desejável para o campo tomando uma série de linhas de problematização. Neste artigo, optou-se por perscrutar a linha que mira as posições designadas a animais nesses materiais didáticos. Isso é feito pois, o procedimento de análise dessas redes toma como mote as atribuições a animais nos materiais analisados. Principalmente os modos de relacionamento entre humanos e animais que são indagados para descrever as subjetivações produzidas no campo.

Além disso, esse artigo também busca trazer contribuições metodológicas para a área de investigações na qual se insere: a Educação Matemática. $O$ tratamento dos dados foi realizado por meio do uso de dois softwares: um de análise qualitativa (Atlas TI) e outro de análise de redes sociais (Gephi). Juntos, esses dois softwares possibilitaram a otimização do trabalho analítico, bem como garantiram a viabilidade de inquirição com uma grande quantidade de dados; as 160 codificações produzidas geraram um total de 1536 excertos. Esses excertos são imagens, textos, fotografias, atividades, exercícios e orientações para o professor, os quais receberam um tratamento de seleção, catalogação e análise a fim de mapear moralidades, valores e práticas que circulavam nos dez livros didáticos de Matemática e construíam um conjunto de subjetividades endereçadas aos habitantes do campo. A análise do discurso foucaultiana baliza esse procedimento, bem como a análise do conceito conectado, ambas as teorizações serão discutidas na sequência.

Antes, é preciso esclarecer que os 160 códigos construídos tentam percorrer os processos de subjetivação anunciados, todavia, neste artigo serão perscrutados apenas 28 desses códigos. 
Os modos como eles se relacionam serão a principal fonte de interesse que leva ao uso do software de análise de redes, interpretamos que esta é uma forma de tornar visível a rede discursiva que emergiu do procedimento analítico.

Os códigos foram elaborados a partir da leitura atenta dos materiais e respectiva organização das categorias construídas com as lentes, principalmente, dos Estudos Animais. A partir disso, nossas análises neste artigo descrevem a frequência bem como as coocorrências dos códigos em relação à disposição dos animais nesses materiais. Interpretamos que esse procedimento permite entender a dinâmica dos efeitos de subjetividade operados por meio da produção de maneiras ótimas e positivas de relacionamento humano com animais. Afirmamos que a descrição nos materiais de usos corpos, atributos a esses e funções dos animais produz e ratifica um conjunto de práticas assumidas como inerentes e potentes aos modos de vida que acontecem no campo, sendo essas imbuídas de um status de verdade ratificada tanto pela presença no livro didático quanto referendada pelo conhecimento matemático, com seu valor agregado tanto nos âmbitos social e econômico, que institui por meio de discursividades uma racionalidade neoliberal que extrai desse relacionamento (animais-humanos) condições para a estabilização dos modos de vida que operam nessa lógica.

É importante salientar que não interpretamos os códigos como enunciados, afinal este é uma "[...] função que cruza um domínio de estruturas e de unidades possíveis e que faz com que apareçam, com conteúdos concretos, no tempo e no espaço" (FOUCAULT, 2008, p. 98), portanto, é a partir de toda a estrutura gerada no Gephi que as redes terão possibilidade de serem descritas e analisadas. Isso será melhor discutido nas próximas seções.

A seguir, inicialmente serão descritas as teorizações que suportam as estratégias metodológicas. Na sequência, uma apresentação sintética das 28 codificações elaboradas será discutida para, finalmente, os grafos com os resultados da investigação serem perquiridos.

\section{Redes discursivas}

Nesta investigação, as redes discursivas nos auxiliam tanto na construção dos códigos quando no tratamento e análise sobre eles produzidos. Nossa interpretação é de que as redes compõem um certo tipo de campo de estabilização (FOUCAULT, 2008) em que enunciações heterogêneas são postas em conjunto (no livro didático de Matemática para os anos iniciais do 
campo, por exemplo) constituindo assim "[...] práticas que formam sistematicamente os objetos de que falam" (FOUCAULT, 2008, p. 55).

O livro didático como importante elemento do currículo, organiza dinâmicas escolares materializa práticas do seu tempo, comporta noções, valores e moralidades concernentes, balizadas e ratificadas por saberes, constitui enunciações e, consequentemente, elabora redes discursivas.

Os saberes mencionados, não se restringem a um tipo de conhecimento, tal como a Matemática escolar, por exemplo. Num jogo de forças que produz esses saberes, estamos assumindo que, com base nas teorizações foucaultianas, os enunciados que emergem da análise desses livros funcionam estrategicamente em um tempo, essa é aliás uma das maiores contribuições do pensamento desse filósofo: "as falsas generalidades e os discursos variam através do tempo; mas, em cada época, passam por verdadeiros. De tal modo que a verdade é reduzida a dizer a verdade, a falar conforme o que se admite ser verdade [...]" (VEYNE, 2018, p. 19).

Desse modo, pautar a investigação por meio de um projeto arqueológico, implica analisar as relações de força que produzem discursividades localizadas e esse, tal como já anunciava Foucault (1998), se exerce não por imposição ou violência, mas opera pela produção de discursividades que funcionam assentadas em noções robustas de verdade. Nesse sentido, "0 poder deve ser analisado como algo que circula, ou melhor, como algo que só funciona em cadeia. Nunca está localizado aqui ou ali, nunca está nas mãos de alguns, nunca é apropriado como uma riqueza ou um bem. O poder funciona e se exerce em rede" (FOUCAULT, 1998, p. 183) e essas, as maneiras como cada código se repele, se atrai e se relaciona que guiarão as análises.

\section{Estudos Animais}

Fazer emergir práticas tidas como cotidianas do campo em seus desdobramentos na relação humano/animal, é um procedimento que visa problematizar e evidenciar para que se possa sobre elas realizar um profundo e profícuo exercício de análise a fim de descrever os efeitos dessas práticas em modos de vida localizados.

Os "Estudos Animais" como campo de investigações abarcam uma série de pesquisas que muito recentemente entraram no cenário dos debates acadêmicos no Brasil, com origem 
irrevogável junto aos movimentos que debatem os direitos animais. Todavia, a área não se limita à militância da causa animal, mas incorpora um amplo espectro de problematização acerca da alteridade animal. Mesmo assim, parece não haver um consenso sobre a constituição desse como campo de pesquisa. Guida (2016, p. 22) aponta a irresolução da área e questiona: "há quem diga que se trata de uma teoria [...] Crítica literária? Apenas ativismo? Tudo isso pode perpassar os Estudos Animais". Na área de linguagens e ciências biológicas, parece que o campo tem se percebido mais estável:

(...) vêm se afirmando como um espaço de entrecruzamento de várias disciplinas oriundas das ciências humanas e biológicas, em torno de dois grandes eixos de discussão: o que concerne ao animal propriamente dito e à chamada animalidade e 0 que se volta para as complexas e controversas relações entre homens e animais não humanos. Torna-se, portanto, evidente a emergência do tema como um fenômeno transversal, que corta obliquamente diferentes campos do conhecimento e propicia novas maneiras de reconfigurar, fora dos domínios do antropocentrismo e do especismo, o próprio conceito de humano. (MACIEL, 2011 apud VIZACHRI, 2015, p. 3).

Nesse sentido, as intersecções que as marcas culturais operaram e ainda hoje operam sobre o racismo e o sexismo, por exemplo, produzindo efetivamente modos de relacionamento pautadas por mecanismos de subalternização entre classes humanas são também eixos analíticos dos quais se servem os pesquisadores desse campo:

\begin{abstract}
Os estudos animais apresentam como horizonte questionar se o antropocentrismo também estaria de alguma maneira ligado ao especismo, racismo, sexismo ou a qualquer outra forma de expressão de soberania, poder e subjugação do outro. [...] A exemplo dos animais, mulheres, negros, índios e todos aqueles que representam a "minoria" diante do pensamento hegemônico e falocêntrico tendem a ser diminuídos e/ou excluídos de alguma maneira. (GUIDA, 2016, p. 24-25)
\end{abstract}

Apesar desta argumentação bastante recorrente entre os investigadores dos Estudos Animais, Weil (2012) alerta que as demandas em questões de gênero e de raça, por exemplo, são diferentes sobre questões de espécies - porque as pessoas marginalizadas por racismo e sexismo demandam que suas reivindicações e suas vozes sejam atendidas e respeitas, o que não é o caso dos animais.

De todo modo, todos esses movimentos se pautam por lançar luz sobre a genealogia das classificações acerca de determinados corpos, aqueles que não importam. Nessa direção, Giorgi (2016) toma as evocações dos animais em materiais diversos para problematizar as dinâmicas 
políticas e culturais que distribuem o que conta como pessoa e como não-pessoa, evidenciando as contingências temporais e instáveis desses movimentos.

\section{Análise do Conceito Conectado}

Esse método de análise possibilita interpretação tanto qualitativas quanto quantitativas do material de pesquisa e mostrou-se bastante pertinente para perquirir os livros didáticos frente ao entendimento da Matemática escolar como política cultural (VALERO, 2018). De acordo com Lindgren (2016), com essa estratégia é possível "medir os discursos" (p. 342) pois toma a análise de redes e as teorias do discurso para construir uma interpretação apurada do conjunto de dados. Ainda, tomar esse método para potencializar discursos privilegiados no conjunto de dados permite identificar os pontos nodais, ou seja, "(...) um discurso pode ser visto com um campo ou espaço onde um número de componentes simbólicos ou conceitos são posicionados um em relação ao outro. Alguns desses conceitos são periféricos, enquanto outros são cruciais ou centrais (pontos nodais)" (LINDGREN, 2016, p. 348).

Além disso, foi utilizado o procedimento de análise de redes na investigação, que consiste basicamente em estudar as métricas de nós e arestas, sendo essas informações essenciais para que se utilize a ferramenta em suas potencialidades. Esta não é novidade na Educação Matemática e remete à noção de um espaço construído a partir do entrelaçamento de um conjunto de fios. Por meio das redes, as relações e as posições atribuídas aos animais foram mapeadas. Para isso, foi utilizado o software Gephi 0.9.2 em que foram descarregadas matrizes de frequência e coocorrência geradas em outro software, o Atlas TI 8.

Assim, foi possível analisar os grafos e as métricas obtidos, a fim de inferir sobre as estruturas fornecidas, dando-lhes sentido.

Todos os dados foram codificados manualmente e inseridos em uma tabela de códigos que destacou as enunciações associadas aos animais, afinal, descrever essas regularidades é um exercício que possibilita entendê-las como contingentes em tempos e espaços específicos pois estes operam "[n]esse feixe complexo de relações que 'faz' com que certas coisas possam ser ditas (e serem recebidas como verdadeiras), num certo momento e lugar" (FISCHER, 2003, p. 373). 
A análise do discurso possibilita examinar as diferentes maneiras pelas quais um sistema estratégico de poder funciona, é normalizado e mobiliza práticas. E isso ganha potência a partir das noções da "análise do conceito conectada", pois entende-se que esse método evidencia discursos privilegiados no conjunto de dados, permitindo identificar pontos nodais, pois "(...) um discurso pode ser visto como um campo ou um espaço em que um número de componentes simbólicos ou conceitos são posicionados em relação um com o outro" ((LINDGREN, 2016, p. 348). Os pontos nodais, portanto, são interpretados como constituintes da rede discursiva e, por meio da descrição e análise desses, é possível tornar evidentes as interações, tensões, combinações, rearranjos que culminam por constituir um conjunto de práticas que permite reconhecer esse sujeito desejável no contexto do campo, mirado nas relações que (deveria) estabelece(r) com os animais.

Ao todo, foram identificadas 503 menções a animais nos dez livros, inicialmente todas essas menções foram rotuladas em uma das quatro codificações acerca dos modos de apresentação desses animais, são elas: Desenho (quando os animais apareceram desenhados), Reais (quando fotos de animais foram expostas), Citação (quando não há imagens, somente referência a animal) e Ocultos (quando os animais não são mencionados, mas há a abordagem de um subproduto deles). Nesta investigação, pretende-se que esses quatro códigos auxiliem 0 processo analítico de descrição e mapeamento dos lugares ocupados por e atribuídos aos animais.

Após essa primeira organização, a qualidade dessas aparições mereceu o perquirir e, desse exercício, as 503 menções a animais foram classificadas de acordo com 24 enunciações identificadas, são essas: Alimento; Alimentos para outros animais; Animais em extinção; Antropomorfização; Apicultura; Caça; Carne; Cuidados com os animais; Estimação; Felizes; Granja de aves; Granja porcos; Hábitos dos animais; Leite e derivados; Livres; Meio de transporte; Ovos; Pecuária; Peles de animais; Perigosos; Pesca; Preso; Propriedade e Trabalho.

Na próxima seção, serão discutidos cada um desses 28 códigos elaborados.

\section{Dimensão: Estudos Animais}

Este artigo, como parte de uma tese, apresenta resultados do que optou-se por denominar "Dimensão Estudos Animais", em que são discutidos os resultados acerca da produção de subjetividades que emanam das posições atribuídas a animais, bem como dos modos de 
relacionamento entre esses e humanos apresentados no material analisado. Nessa dimensão, a intenção foi descrever como os animais são posicionados, suas funções e atribuições descritas nos materiais didáticos de modo a implicar num conjunto de valores, moralidades e comportamentos adequados e potencializadores de práticas no contexto do campo. Com o auxílio das ferramentas metodológicas apresentadas neste artigo, a intenção é percorrer toda essa dimensão a fim de descrever as discursividade que emergem da análise da rede.

O primeiro exercício será apresentar as codificações elaboradas. Como já anunciado, os animais foram primeiramente categorizados em quatro formas de aparição: desenho, citados, reais e ocultos. Esse procedimento foi elaborado para abordar as maneiras como os animais são posicionados nesse material, principalmente quando se leva em conta o público alvo desses materiais: crianças cursando os anos inicias do Ensino Fundamental, ou seja, indivíduos que, em geral, têm entre 5 e 11 anos. Na sequência, os 24 códigos são descritos e organizados no Quadro 1 para, depois disso, comporem as análises realizadas.

Quadro 1: Descrição dos Códigos

\begin{tabular}{|c|c|c|}
\hline & Código & Descrição \\
\hline & Animais Livres & $\begin{array}{l}\text { Esse código surge da constatação de que, especialmente nas ilustrações } \\
\text { idílicas do campo, os animais não apareciam encarcerados. Quando eles } \\
\text { são apresentados a partir de fotografias ou apenas citados, esse } \\
\text { posicionamento de haver ou não um cerceamento explícito, não fazia } \\
\text { sentido. Só houve essa rotulação quando havia um contexto claro acerca } \\
\text { do local de habitação desses animais. Em relação a "animais livres", foram } \\
199 \text { ocorrências. }\end{array}$ \\
\hline & Animais Presos & $\begin{array}{l}\text { A partir do mesmo critério utilizado para tratar "Animais Livres", o resultado } \\
\text { foi essa posição ser mais comum nos animais enquanto desenho. Foram } \\
23 \text { aparições. Um resultado interessante foi a ocorrências de } 9 \text { imagens } \\
\text { em que há interseção entre esses dois códigos (livres e presos). Todas } \\
\text { essas referem-se a imagens em que alguns animais são posicionados } \\
\text { presos, enquanto outros estão livres, um clássico exemplo disso era } \\
\text { quando animais considerados "de estimação" (cachorros e gatos) eram } \\
\text { posicionados livres enquanto animais para "o trabalho" (vacas) estavam } \\
\text { presos. }\end{array}$ \\
\hline & $\begin{array}{l}\text { Animais como } \\
\text { propriedade }\end{array}$ & $\begin{array}{l}\text { Esse código seleciona animais explicitamente anunciados como uma } \\
\text { propriedade dos humanos. Palavras como criar, ter (animais), entre outras, } \\
\text { são marcadores dessa seleção. Quando há referências a "animal de } \\
\text { estimação", optou-se por colocar em um código separado. Entende-se, } \\
\text { claro, que o animal de estimação é tratado como uma propriedade } \\
\text { humana, mas ele difere em uma infinidade de situações em relação as } \\
\text { condições de vida dada a outros animais que não são tomados na relação } \\
\text { com humanos por meio do afeto, tal como se supõe serem os animais de }\end{array}$ \\
\hline
\end{tabular}




\begin{tabular}{|c|c|}
\hline & $\begin{array}{l}\text { estimação. Todavia, de um total de } 31 \text { referências a animais como } \\
\text { propriedade, houve cinco excertos em que a categoria "animal de } \\
\text { estimação" aparecia concomitantemente. Nesses casos, as instruções e } \\
\text { atividades requeriam do aluno a classificação dos animais entre "de } \\
\text { estimação" ou "de criação" ou o lugar adequado onde eles podem ser } \\
\text { alocados nos lares no campo. }\end{array}$ \\
\hline $\begin{array}{l}\text { 4. Animais } \\
\text { ameaçados de } \\
\text { extinção }\end{array}$ & $\begin{array}{l}\text { Ao longo de um total de } 22 \text { referências, há uma manifestada preocupação } \\
\text { com os animais, especialmente os silvestres, em risco de extinção. Os } \\
\text { estudantes são convocados a refletir e se responsabilizar sobre a } \\
\text { necessidade de evitar o processo de desaparecimento de determinadas } \\
\text { espécies. Todavia, com exemplos de animais já extintos como } \\
\text { dinossauros, por exemplo, o ser humano é isentado de responsabilidade. } \\
\text { De todo modo, o objetivo é que os estudantes se engajem e expressem } \\
\text { suas opiniões acerca dos animais que se encontram em risco de extinção, } \\
\text { enquanto os professores são orientados a problematizar esses } \\
\text { acontecimentos. Nesse código, boa parte dos animais elencados faziam } \\
\text { parte dos denominados "animais silvestres". }\end{array}$ \\
\hline $\begin{array}{l}\text { 5. Animais de } \\
\text { estimação }\end{array}$ & $\begin{array}{l}\text { Imagens de cachorros e gatos, sempre numa posição passiva foram } \\
\text { alocadas a essa classificação, mesmo sem uma menção explícita a sua } \\
\text { função de "estimação". Em outros momentos, houve alusão deliberada ao } \\
\text { papel exercido por esses animais, os espaços que podem ocupar (dentro } \\
\text { ou fora de casa) e, fundamentalmente, sua função ornamental para as } \\
\text { vidas humanas. Fato interessante é uma atividade de classificação dos } \\
\text { animais entre de estimação, para o trabalho e para alimentação, que } \\
\text { alertava professores para o fato de que essa classificação era flexível no } \\
\text { contexto do campo, haja vista que uma galinha de estimação, ao ficar } \\
\text { idosa, poderia servir de alimento. Enfim, ao longo de } 22 \text { menções a } \\
\text { animais de estimação, portanto, foi possível identificar suas atribuições } \\
\text { passivas, os cuidados necessários a esses seres, bem como a hipotética } \\
\text { mobilidade dessa noção no contexto do campo, afinal, o animal pode ser } \\
\text { sempre "aproveitado". }\end{array}$ \\
\hline $\begin{array}{l}\text { 6. Hábitos dos } \\
\text { animais }\end{array}$ & $\begin{array}{l}\text { Neste item, ao que parece, a alteridade animal é tomada para servir de } \\
\text { contexto a exploração de atividades que envolvam Matemática escolar. } \\
\mathrm{Na} \text { maior parte das ocorrências, quase como um processo de } \\
\text { zoomorfização, os hábitos animais são tomados para ensinar aos } \\
\text { humanos acerca de valores e moralidades que devem ser adotadas pelos } \\
\text { humanos. São } 18 \text { ocorrências dessa natureza. }\end{array}$ \\
\hline 7. Animais perigosos & $\begin{array}{l}\text { Nesta categorização, há instruções acerca dos perigos de animais } \\
\text { peçonhentos, bem como os procedimentos tanto para se proteger quanto } \\
\text { para se tratar de ataques feitos por eles. Também os livros esclarecem } \\
\text { acerca da necessidade de combate às pragas nas atividades } \\
\text { agropecuárias. Essa categoria apareceu somente na coleção que não } \\
\text { divide fisicamente os conteúdos de Matemática e Ciência, portanto, é } \\
\text { possível inferir que essa temática está muito mais vinculada às atividades } \\
\text { que buscam contemplar conteúdos de Ciências. Foram } 11 \text { ocorrências } \\
\text { dessa categoria. }\end{array}$ \\
\hline
\end{tabular}




\begin{tabular}{|c|c|c|}
\hline & $\begin{array}{l}\text { Animais para a } \\
\text { alimentação }\end{array}$ & $\begin{array}{l}\text { Nesta categoria, foram selecionadas menções explícitas ao uso dos } \\
\text { animais para a alimentação humana. Foram identificadas } 8 \text { ocorrências } \\
\text { dessa natureza. Todas elas são referentes a uma das coleções, na outra, } \\
\text { não foram encontradas atividades que explorassem os animais em sua } \\
\text { privação de vida a favor de se tornarem alimento para humanos. }\end{array}$ \\
\hline & $\begin{array}{l}\text { Animais para } 0 \\
\text { trabalho }\end{array}$ & $\begin{array}{l}\text { Além de uma classificação marcada quando às utilidades dos animais, } \\
\text { supõe-se que essas ocorrências aparecem no contexto desses materiais, } \\
\text { por serem elaborados para as populações que habitam o campo, local } \\
\text { onde isso é tido como componente inquestionável das práticas cotidianas. } \\
\text { São } 15 \text { ocorrências dessa atribuição aos animais. }\end{array}$ \\
\hline & $\begin{array}{l}\text { Animais como } \\
\text { alimento para } \\
\text { outros animais }\end{array}$ & $\begin{array}{l}\text { Neste item, alguns animais são apresentados como se alimentando de } \\
\text { outros animais. Nos materiais analisados, o ciclo de vida dessas espécies } \\
\text { está totalmente relacionado ao consumo de outros seres vivos, a caça e o } \\
\text { consumo de animais de menor porte. Nas } 10 \text { ocorrências dessa categoria, } \\
\text { os conteúdos de medida e classificação foram os mais elaborados a partir } \\
\text { deste conteúdo. Esse código foi elaborado pois tendia a justificar as } \\
\text { mesmas práticas em humanos }\end{array}$ \\
\hline & $\begin{array}{l}\text { Animais como } \\
\text { meio de transporte }\end{array}$ & $\begin{array}{l}\text { Em mais uma categorização que visa à discussão da utilidade dos } \\
\text { animais, um total de } 7 \text { menções explícitas ao uso desses corpos como } \\
\text { meio de transporte foi contabilizado. Os denominados veículos de tração } \\
\text { animal foram os mais recorrentes, talvez essa pudesse ser também } \\
\text { alocada na categoria de "animais para o trabalho", todavia optou-se por } \\
\text { alocá-la separadamente para uma mais acurada análise. }\end{array}$ \\
\hline & Animais felizes & $\begin{array}{l}\text { Todas as } 187 \text { ocorrências de animais com expressões sorridentes, alegres } \\
\text { ou felizes estão alocadas na categoria de animais como desenho, ou seja, } \\
\text { é também um processo de antropomorfização, em que aos animais são } \\
\text { atribuídas manifestações que são necessariamente da natureza humana, } \\
\text { não de natureza animal, como sorrir, por exemplo. }\end{array}$ \\
\hline & Antropomorfização & $\begin{array}{l}\text { Essa categorização surgiu da identificação de um total de } 197 \text { ocorrências } \\
\text { de animais exercendo atividades humanas. Nesses casos, os animais são } \\
\text { apresentados como personagens realizando práticas humanas. }\end{array}$ \\
\hline & Apicultura & $\begin{array}{l}\text { Foram identificadas apenas } 2 \text { menções à prática da apicultura por meio da } \\
\text { criação de abelhas para extração de seu mel. Uma atividade em cada } \\
\text { coleção foi catalogada, ambas eram tomadas como contexto para que os } \\
\text { alunos realizassem atividades que envolviam contagem e operações } \\
\text { aritméticas. }\end{array}$ \\
\hline & . Caça & $\begin{array}{l}\text { Essa atividade foi identificada ao longo de } 11 \text { aparições nos materiais } \\
\text { didáticos. Ela está bastante associada a outra categoria que é a "animais } \\
\text { ameaçados de extinção", associando a responsabilização do habitante do } \\
\text { campo para que exerça sua cidadania e projeta o ambiente no qual vive, } \\
\text { enquanto em outras oportunidades aparece como atividade intrínseca das } \\
\text { práticas humanas. }\end{array}$ \\
\hline \multicolumn{2}{|c|}{ 16. Peles } & $\begin{array}{l}\text { Em somente } 4 \text { ocorrências, essa categoria acontece em apenas uma das } \\
\text { coleções. Para os conteúdos de Matemática, é tema para abordar padrões }\end{array}$ \\
\hline
\end{tabular}




\begin{tabular}{|c|c|}
\hline & $\begin{array}{l}\text { geométricos. Como também trata de animais silvestres, o tema é abordado } \\
\text { para falar da necessidade de preservação de espécies em extinção. }\end{array}$ \\
\hline $\begin{array}{l}\text { 17. Cuidado com os } \\
\text { animais }\end{array}$ & $\begin{array}{l}\text { Ao longo de } 9 \text { ocorrências, essa categoria clama à responsabilização dos } \\
\text { habitantes do campo para com os animais. }\end{array}$ \\
\hline 18. Pesca & $\begin{array}{l}\text { As atividades de pesca foram catalogadas } 22 \text { vezes ao longo do material } \\
\text { analisado. Em alguns momentos é descrita como de trabalho desde os } \\
\text { tempos mais remotos enquanto em outras situações, como de natureza } \\
\text { lúdica, como atividade de esporte e/ou lazer das populações que habitam } \\
\text { o campo. Mesmo assim, por vezes, há alertas às "práticas responsáveis" } \\
\text { para preservação das espécies. }\end{array}$ \\
\hline 19. Pecuária & $\begin{array}{l}\text { Nesta seção foram alocadas todas as referências explícitas às atividades } \\
\text { de pecuária, bem como as ilustrações em que os animais apareciam em } \\
\text { currais, amarrados ou em qualquer outra posição que indicasse ser } \\
\text { manejados para tal atividade econômica. Foram identificadas } 35 \\
\text { referências dessa natureza. Há menção explícita ao abate para produção } \\
\text { de proteína animal e, também, a produção de leite. Todavia, nem sempre } \\
\text { há a menção a algum animal nesta categoria. O que reforça o apagamento } \\
\text { do produto em relação a sua origem. }\end{array}$ \\
\hline 20. Leite e derivados & $\begin{array}{l}\text { Nesta codificação, foram listadas todas as referências a leite e quaisquer } \\
\text { outros produtos que sejam seus derivados. O código "leite" esteve muito } \\
\text { mais associado ao código oculto, uma vez que os leites eram só citados, } \\
\text { sem revelar sua origem. Foram } 41 \text { menções ao longo dos materiais } \\
\text { analisados. }\end{array}$ \\
\hline 21. Granja de aves & $\begin{array}{l}\text { Nesta seção foram tomadas as ilustrações em que as aves eram } \\
\text { representadas em locais fechados, os denominados galinheiros, em que } \\
\text { havia menção à criação de aves para produção de ovos, principalmente. } \\
\text { Foram } 15 \text { manifestações dessa natureza. }\end{array}$ \\
\hline 22. Carne & $\begin{array}{l}\text { Ao longo de } 21 \text { menções à carne, há somente duas que fazem referência } \\
\text { a carne de frango. Em outras ocorrências, peixes resultantes das } \\
\text { pescarias (ou seja, mortos) apareciam em ilustrações, neste caso, e foram } \\
\text { alocadas a este código. }\end{array}$ \\
\hline 23. Ovos & $\begin{array}{l}\text { Foram } 30 \text { referências a ovos ao longo do material analisado. Em quase } \\
\text { metade das ocorrências, os ovos eram associados as galinhas, ou seja, } \\
\text { diferentemente do código "carne", a origem dos ovos não foi sempre } \\
\text { apagada. }\end{array}$ \\
\hline 24. Granja de Porcos & $\begin{array}{l}\text { Esse código aparece em apenas } 3 \text { referências somente em uma das duas } \\
\text { coleções analisadas. E menciona a criação de porcos para diversos, e não } \\
\text { anunciados, fins. }\end{array}$ \\
\hline
\end{tabular}

Fonte: Elaboração das Autoras 


\section{Análises}

Comumente utilizados para analisar comportamentos de usuários em redes sociais, softwares como o Gephi também apresentam potencialidade imagética e relacional caras à investigação aqui produzida. A análise do discurso foucaultiana, associada ao software, é tomada para dar um tratamento qualitativo mais apurado aos resultados obtidos da interpretação dos grafos. Assumimos que essas duas ferramentas auxiliam no tratamento de elementos tão heterogêneos. 0 exercício é explorar a potência de produção de subjetividades que disparam.

Neste artigo, duas análises balizarão o trabalho: a frequência e a coocorrência dos códigos. O processo de análise gerou codificações que foram computadas e resultaram em planilhas eletrônicas, subsequentemente descarregadas no Gephi, gerando grafos que serão discutidos neste tópico. Neste trabalho, cada nó é um dos 28 códigos anteriormente apresentados enquanto as arestas representam as relações entre eles. Importante esclarecer que os 4 códigos principais (citados, desenhos, ocultos e reais) não se relacionam entre si, ou seja, não há coocorrências entre esses quatro pois a função deles é justamente cobrir as outras 24 atribuições qualitativas aos animais nos livros didáticos. Os grafos foram gerados com o auxílio do algoritmo ForceAtlas 2 que distribui a rede pela força de atração e repulsão, funcionando como um sistema físico que distribui os nós e regula as arestas de acordo com as relações estabelecidas entre os nós (quanto mais distante um nó, menos ele se relaciona com os outros, por exemplo).

O Gephi permite usar uma grande variedade de métricas e ferramentas, sendo um software capaz de fornecer estruturas potentes para o tratamento de um número muito grande de dados. É fato que, em nossas análises, apenas uma pequena parcela de todas as ferramentas e potencial do programa foi utilizado, mesmo assim, a intenção é trazer os resultados obtidos a fim de corroborar tanto com a pertinência do uso aqui feito quanto das possibilidades que ainda podem ser exploradas.

$\mathrm{Na}$ Figura 1, buscamos mapear as relações estabelecidas entre os 4 códigos principais (citados, desenho, ocultos e reais) e as outras 24 codificações a fim de descrever qualitativamente as posições atribuídas a esses animais nos livros didáticos. Dessa maneira, ele nos mostra como os quatro códigos cobrem esses personagens onipresentes no contexto do campo.

O resultado do tratamento feito no Gephi mostrou que os 28 nós (os 4 principais relacionados com os outros 24), resultaram num total de 70 arestas, isso significa que alguns dos 24 nós não se relacionaram com um ou mais dos 4 principais, ou seja, tiveram peso (wheight) 0 , 
daí não resultam em uma aresta. Para tratar a rede resultante, as métricas escolhidas para o grafo ilustrado na Figura 1 permitiram eleger o atributo ranking de "grau ponderado" para a cor, que vai do verde à cor rosa, com variação no tom dessas cores. Isso significa que quando mais cor rosa, maior é o número de conexões que chegam a esse nó (mais densa são as arestas). Em um sentido oposto, quanto mais verde o nó, menos conexões chegam a ele.

Outra escolha feita foi em relação ao tamanho do nó, para isso adotamos o atributo "Betweness centrality": quanto maior o nó, mais interações ele tem com nós diferentes.

Portanto, nas escolhas realizadas, a cor (quanto mais cor de rosa) indica a efetividade de relação desses nós (quantidade de interações), enquanto o tamanho indica a popularidade desses nós no contexto da rede (quantidade de nós com os quais interage).

Lembrando que, devido ao algoritmo ForceAtlas2, quanto mais distante um nó, menos interações com outros nós da rede. Assim, é possível passar a analisar os padrões de conexão obtidos no Grafo ilustrado na Figura 1.

Nesse grafo, devido às métricas escolhidas, é possível observar que o nó "Citados" interage substantivamente com os outros, por ser maior. Em um outro sentido, é possível inferir que o "desenho", apresenta um peso (quantidade de conexões) bem mais significativo (o cor de rosa desse nó é bastante destacado em relação aos outros), seu oposto seria o código "reais" visto que apresenta um tom verde bem mais destacado.

O peso desse nó também pode ser deduzido ao verificarmos o quanto as arestas em torno dele são mais espessas, ou seja, a conectividade entre eles é consideravelmente pesada (isso se dá sobretudo com os códigos "felizes", "livres" e "antropomorfização"). Já o nó "Apicultura", ao contrário, está distante do único tipo de representação (citados) com o qual se relaciona. Quando há o apagamento do animal enquanto origem daquilo que se está mencionando representado pelo código "ocultos", existe uma discreta conexão com os outros, excetuando-se pelos nós "Leite e derivados", "ovos" e "carne", visto que esses se destacam principalmente pelo apagamento de sua origem. Isso é bastante curioso no contexto do campo visto que há uma constante dedução da vida nesse ambiente como intrínseca do relacionamento com os animais, em um sentido de uso naturalizado de suas vidas e de seus corpos para o trabalho, isso, aliás, é temática para abordagem dos conteúdos junto aos alunos, conforme a orientação para os professores que aparece em um dos textos analisados: "explorar, por meio de relatos orais, o contato dos alunos com os animais. Explorar a relação do ser humano com os animais. Aprender que a domesticação 
dos animais permitiu ao ser humano criar animais para a alimentação e outras finalidades" (GOMES et al., 2014a, p. 251).

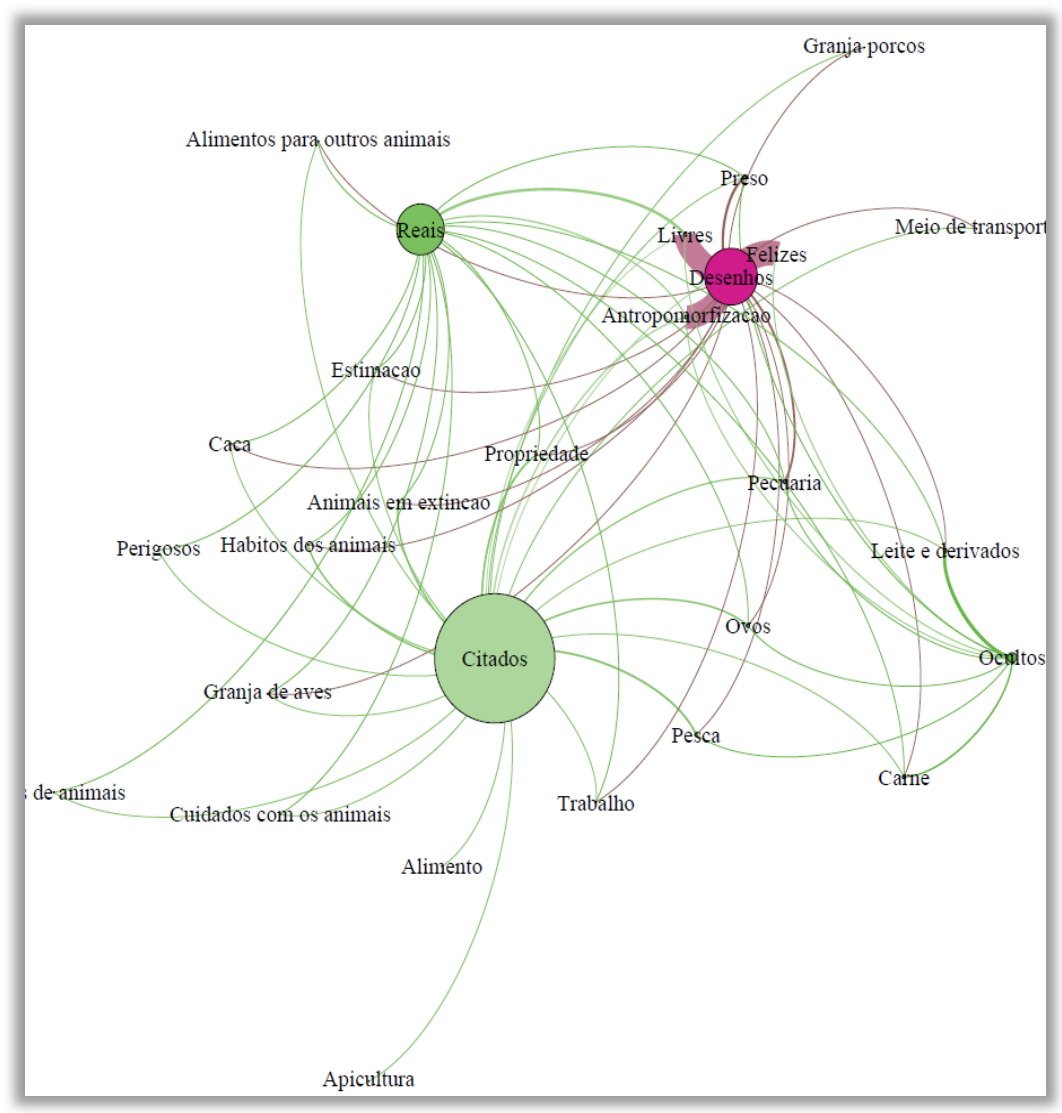

Figura 1: Grafo de Frequência (Elaboração das Autoras)

Na próxima ilustração, Figura 2, outro aspecto bastante pertinente dos mesmos resultados é abordado: as comunidades formadas de acordo com as interações entre os nós.

No grafo ilustrado na Figura 2, para o tamanho dos nós, a métrica continua sendo 0 "Betweness centrality", no entanto, para as cores agora tomamos a "Modularity class". Essa métrica fornece informações acerca dos grupos formados de acordo com as conexões estabelecidas. Nesse grafo os resultados mostram que há 3 comunidades, como pode ser observado na referida figura.

Isso significa que as interações de vários nós com os códigos "reais" e "citados" se dão de maneira mais relevante - tanto que esses aparecem com um azul bem forte - enquanto os outros dois códigos principais, "desenho" e "oculto" formam cada um, outra comunidade. 


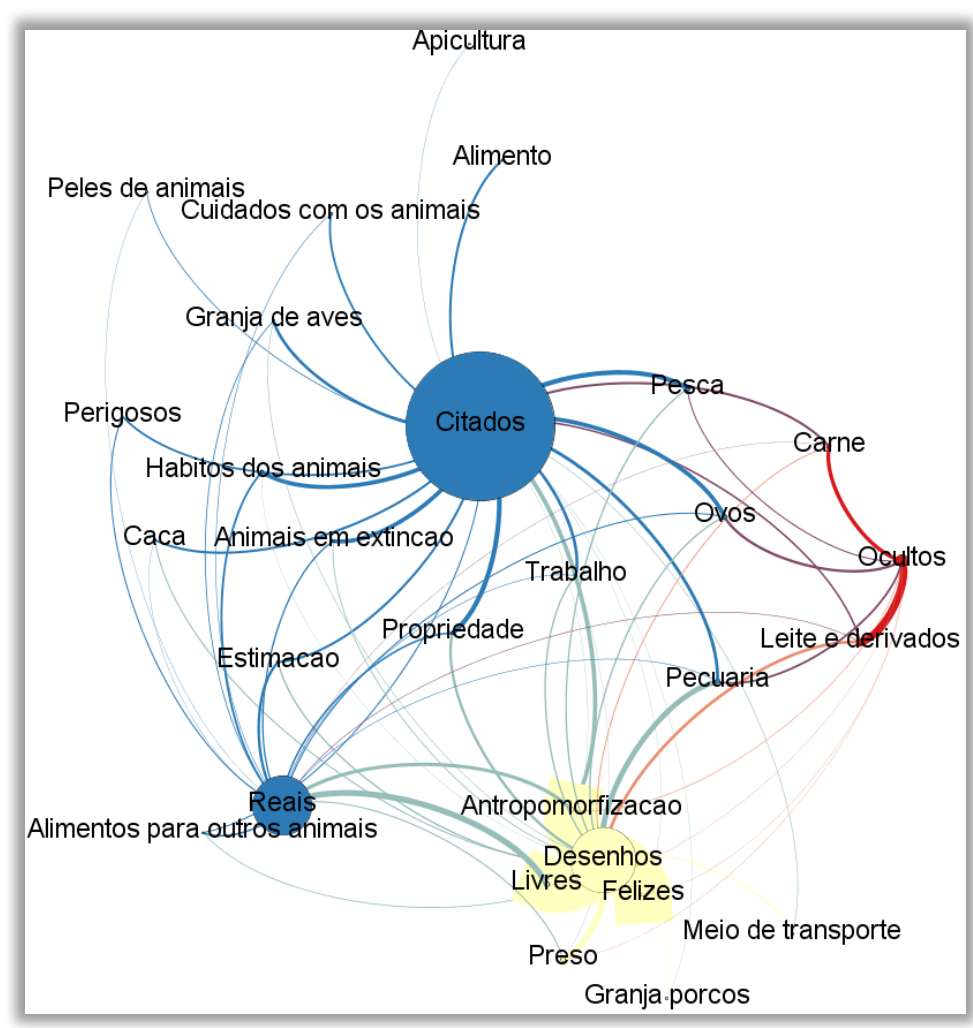

Figura 2: Grafo de Frequência: Análise de Comunidades (Elaboração das Autoras)

O que tanto a Figura 1 quanto a 2 evidenciam é que quando os animais são "citados" o conjunto de atividades e posições a eles atribuídas é muito mais amplo. Aliás, o código "citados" tem grau 24, o que significa que ele é o único que se relaciona com todos os outros 24 códigos. Esse fato adicionado à formação de comunidade com o código "real" (Figura 2) coloca esses nós muito mais relacionados à indicação de trabalho com os animais e as atribuições do trabalhador do campo para com eles.

Essa comunidade marcada em azul, também indica que, associadas a esses códigos principais (citados e reais), os animais enquanto seres que necessitam de atenção e dedicação são substantivamente relacionados: "você pode também mencionar que a criação de animais terrestres e a aquicultura são modos de evitar a caça e a pesca, ajudando a preservar a natureza" (GOMES et al., 2014b, p. 228), isso é associado a um conjunto de prática que diz sobre o trabalho e a potencialização desse, como já destacado em Neto e Valero (2018), ou seja, a necessidade de zelo e preservação dos animais se associa a um discurso de responsabilidade ambiental ao mesmo tempo em que valida eticamente o trabalho de gestão dos corpos e das vidas animais com fins lucrativos. Tudo isso obedece à uma racionalidade que se ampara em práticas verdadeiras, na constituição de subjetividades historicamente analisáveis (FOUCAULT, 1995), afinal é muito 
potente, especialmente nos materiais analisados, a ideia de que "as identidades campesinas, articuladas a um espaço sócio-territorial se produzem/reproduzem pelo trabalho na terra e na natureza através de atividades e pelo uso de instrumentos e produtos ([...]presença de animais como suínos, aves e caprinos, bovinos e equinos [...])" (BRASIL, 2015, p. 14) .

Em um outro sentido, os animais enquanto "desenho" desempenham uma função muito mais alegórica nesses livros com uma frequência notadamente maior em relação aos outros códigos, haja vista a espessura das arestas que o ligam aos nós "felizes", "antropomorfização" e "livres".

A combinação dessas formas de manifestação dos animais nos textos didáticos se relaciona de modo a capturar um suposto tipo de relação intrínseca dos modos de vida no campo - e aí os expõe de maneira quase lúdica em forma de desenho - ao mesmo tempo em que endereça e instrui efetivamente sobre como gerir as vidas animais. As conexões estabelecidas entre a atenção a esses seres vivos em codificações tais como "cuidados com os animais" e formas de trabalho que se munem dessas vidas, fica bem mais evidente nas próximas análises.

Essas combinações heterogêneas compõem a rede que subjetiva os modos de relacionamento de humanos com animais, sem ser absolutamente estáveis.

Ao invés de ser uma coisa dita de forma definitiva - e perdida no passado, como a decisão de uma batalha, uma catástrofe geológica ou a morte de um rei -, o enunciado, ao mesmo tempo que surge em sua materialidade, aparece como um entra em redes, se coloca status, em campos de utilização. (FOUCAULT, 2008, p. 118)

As métricas aplicadas nesses dois grafos nos ajudam a compreender a estrutura da rede e, assim, interpretar os nós como constituintes de enunciações que se relacionam e mobilizam outras que as suportam, produzindo, dessa maneira, a rede discursiva anunciada.

Agora passaremos a inquirir os resultados de coocorrência entre as 24 codificações elaboradas. A intenção ao elaborar esse grafo foi analisar o comportamento dos excertos analisados em relação às marcações simultâneas em mais de um código. Ou seja, aqui a os dados auxiliam a entender as interseções entre os 24 códigos e como eles disparam processos de subjetivação por meio dessa estrutura.

As métricas utilizadas foram semelhantes à Figura 1: "grau ponderado" para a cor (do verde para o cor de rosa) e para o tamanho do nó, "Betweenness centrality". 


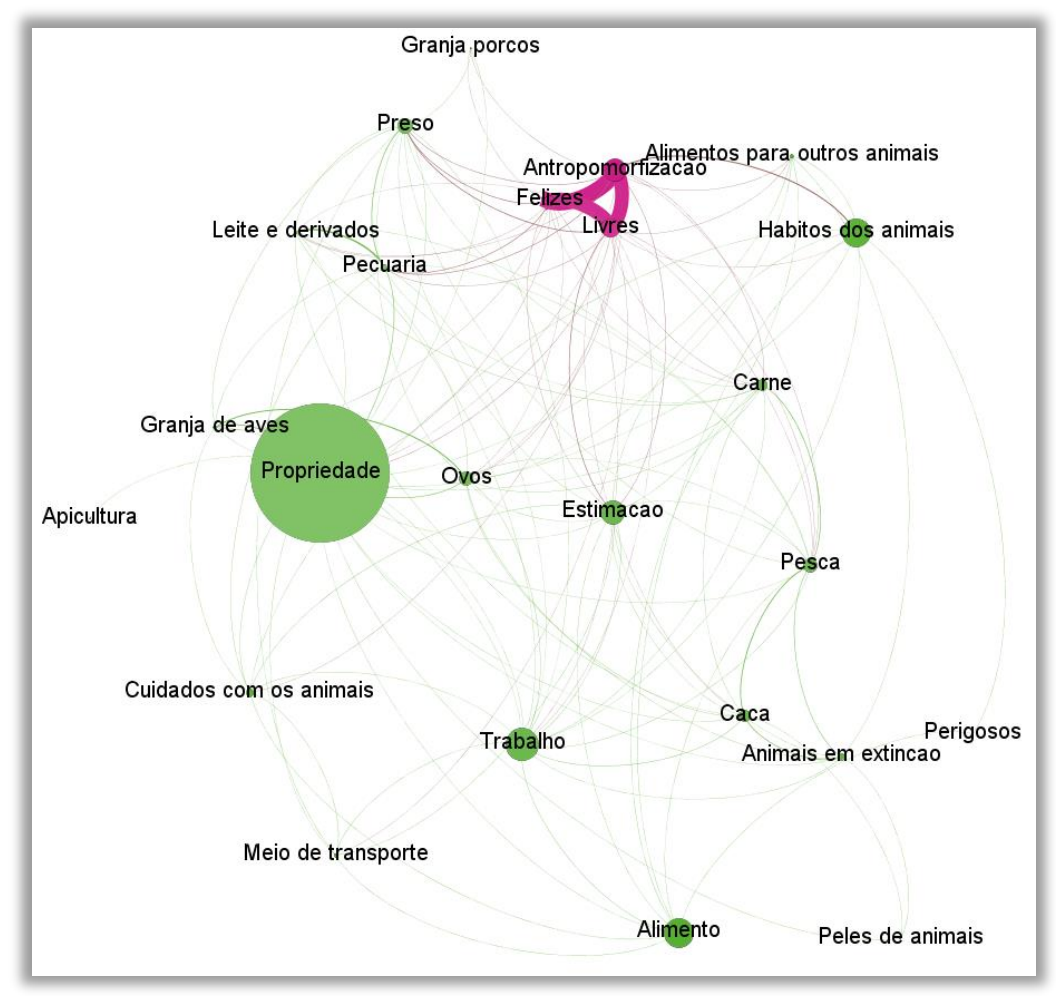

Figura 3: Grafo de coocorrência (Elaboração das Autoras)

No caso dessa rede, ilustrada na Figura 3, exceto por antropomorfização, felizes e livres, não há conexões fortemente estabelecidas entre os nós, ou seja, as arestas não têm espessura considerável. Todavia, as métricas indicam que o grau médio de conexão entre esses nós é de 10,33, ou seja, em média, cada código tem 10 arestas a ele conectados

As arestas, como linhas de interseção entre o que se pressupõe ser a posição do animal, de como ele aparece nesses materiais, refletem no código "propriedades" como aquele que se relaciona com o maior números de outros nós (Betweenness centrality 59,9) com grau igual a 21, o que significa que ele não se relaciona somente com dois códigos, quais sejam, carne e perigosos, as economias da vida e da morte incidem sobre os animais em diversas direções, atribuindo para eles lugares e sentidos em um mapa social.

Quando a métrica utilizada para cores é a "Modularity class", o que se observa é uma rede bastante semelhante à apresentada na Figura 3. Nesse caso há apenas duas comunidades, enquanto em uma delas só aparecem os códigos "felizes", "antropomorfização" e "livres", o restante dos códigos estão todos alocados em outra comunidade. Isso nos permite inferir que mesmo "os animais de estimação" parecem estar relacionados a enunciação acerca das atribuições animais para atender práticas humanas. $E$ isso é ratificado mesmo em um dos textos 
analisados que orienta que "os animais de estimação vivem muito perto das pessoas. Nós criamos cães e gatos, por exemplo, para nos fazer companhia e nos alegrar" (GOMES et al., 2014a, p. 33).

Uma outra enunciação relaciona as formas de aparição animal a seus aspectos lúdicos, que acessam os sujeitos como dispositivo pedagógico (FRIEDRICH, 2010) e são dispostos por meio de moralidades e valores, organizando narrativas que endereçam modos de vida no campo que são positivos, valendo-se de conteúdos matemáticos (NETO, VALERO e GUIDA, 2019) que justificam e ratificam os usos e funções atribuídas a vidas e aos corpos dos animais.

\section{Considerações}

Este artigo é parte de uma incursão que buscou descrever os processos de subjetivação que circulam nos materiais didáticos de Matemática produzidos para os anos iniciais do Ensino Fundamental da Educação do Campo. As codificações elaboradas, bem como os grafos gerados a partir delas, culminaram no entendimento das relações resultantes como redes discursivas que posicionam os animais de formas específicas nos livros didáticos de Matemática, sempre produzindo subjetividades que organizam as vidas humanas no campo, neste caso.

Infere-se que as codificações destacadas relacionam os animais em seus aspectos lúdicos, bem como ao trabalho que sobre suas vidas e corpos pode e deve ser realizado. Ao final, interpretamos que a rede composta incide sobre as noções de afeto e exploração desses seres vivos. As práticas, aparentemente, polarizadas que essa rede explicita, na verdade são linhas heterogêneas que se combinam para validar e moralizar os modos de vida que executam uma relação monetizadora no contexto do campo.

\section{Referências}

BRASIL. Ministério de Educação. Fundo Nacional de Desenvolvimento da Educação. Guia PNLD Campo 2016: Educação do Campo, Ensino Fundamental, Anos Iniciais. Brasília: MEC/FNDE, 2015.

FISCHER, Rosa Maria Bueno. Foucault revoluciona a pesquisa em Educação? Perspectiva, Florianópolis, v. 21, n. 2, p. 371-389, jul./dez. 2003.

FOUCAULT, Michel. A arqueologia do saber. Tradução de Luiz Felipe Baeta Neves. 7. ed. Rio de Janeiro: Forense Universitária, 2008.

FOUCAULT, Michel. Microfísica do poder. Tradução de Roberto Machado. 13. ed. Rio de Janeiro: Editora Graal. 1998 
FOUCAULT, Michel. O sujeito e o poder. In. DREYFUS, Humbert L.; RABINOW, Paul. (Ed.). Michel Foucault, uma trajetória filosófica: para muito além do estruturalismo e da hermenêutica. Tradução de Vera Portocarrero e Gilda Gomes Carneiro. Rio de Janeiro: Forense Universitária, 1995.

FRIEDRICH, Daniel. Historical consciousness as a pedagogical device in the production of the responsible citizen. Discourse: Studies in the Cultural Politics of Education, v. 31, n. 5, p. 649-663, oct. 2010.

GIORGI, Gabriel. Formas comuns: animalidade, literatura, biopolítica. Rio de Janeiro: Roco Digital, 2016.

GOMES, Ligia Baptista; CONDEIXA, maria Cecília Guedes; FIGUEIREDO, Maria Teresinha; VIDIGAL, Sônia Maria Pereira. Alfabetização Matemática e Ciências, $2^{\circ}$ Ano. São Paulo: Global Editora, 2014a.

GOMES, Ligia Baptista; CONDEIXA, maria Cecília Guedes; FIGUEIREDO, Maria Teresinha; VIDIGAL, Sônia Maria Pereira. Alfabetização Matemática e Ciências, $2^{\circ}$ Ano. São Paulo: Global Editora, 2014b.

GUIDA, Angela Maria. Para uma poética do humano e do animal. São Carlos: Pedro \& João Editores, 2016.

LINDGREN, Simon. Introducing connected concept analysis: a network approach to big text datasets. Text \& Talk, v. 36, n. 3, p. 341-362, may. 2016.

NETO, Vanessa Franco; VALERO, Paola; GUIDA, Angela Maria. Anthropomorphism as a pedagogical device in Mathematics textbooks for Countryside Brazil. In: INTERNATIONAL MATHEMATICS EDUCATION AND SOCIETY CONFERENCE, 10, 2019. Proceedings of the MES 10. Hyderabad, 2019, p. 1-10.

NETO, Vanessa Franco; VALERO, Paola. The mathematics textbook for rural population in Brazil: learning to be a modernized farmer. In: CONFERENCE OF THE INTERNATIONAL GROUP FOR THE PSYCHOLOGY OF MATHEMATICS EDUCATION, 42, 2018, Umea. Proceedings of the PME 42. Umea University, 2018, p. 411-418.

VALERO, Paola. Human capitals: school Mathematics and the making of the homus oeconomicus. Journal of Urban Mathematics Education, v. 11, n. 1\&2, p. 103-117, dec. 2018.

VEYNE, Paul. Foucault: seu pensamento, sua pessoa. Tradução de Marcelo Jacques de Morais. Lisboa: Edições Texto \& Grafia, 2009.

VIZACHRI, Tânia Regina. Estudos Culturais e Estudos Animais na compreensão da representação dos animais. $6^{\circ}$ SEMINÁRIO BRASILEIRO DE ESTUDOS CULTURAIS E EDUCAÇÃO e $3^{\circ}$ SEMINÁRIO INTERNACIONAL DE ESTUDOS CULTURAIS E EDUCAÇÃO, 2015, Canoas. Anais do $6^{\circ}$ SBECE e do $3^{\circ}$ SIECE: Educação, transgressões e narcisismos. Canoas: ULBRA/UFRGS, 2015 , p. 52-60.

WEIL, Kari. Thinking Animals: why animal studies now? New York: Columbia University Press, 2012. 